\title{
Lateral continuity of basement seismic reflections in 15 Ma ultrafast- spreading crust at ODP Site 1256
}

\author{
Sreeja Nag(1), Stephen A. Swift(2) \\ (1) Engineering Systems Division \\ Massachusetts Institute of Technology, MA 02139 \\ sreeja_n@mit.edu \\ Summer Student Fellow, Woods Hole Oceanographic Institution \\ Woods Hole, MA 02543. \\ (2) Department of Geology and Geophysics \\ MS\#24, Woods Hole Oceanographic Institution, Woods Hole, MA 02543 USA, \\ sswift@whoi.edu
}

\begin{abstract}
The Ocean Drilling Program (ODP) initiated drilling at Site 1256D in the Guatemala Basin, about 1000km off the East Pacific Rise to penetrate plutonic rocks, anticipated to be relatively shallow in this region, formed at an ultra-fast spreading rate. IODP Expedition E312 successfully drilled into gabbros at 1150m in basement. Multi-channel seismic traces show weak laterally coherent sub-basement reflections at borehole depths. Synthetic reflectivity seismograms were computed using a Ricker wavelet and impedance profiles from borehole sonic logs. These seismograms show significant sub-basement amplitude peaks. A zero-offset vertical seismic profile, shot on E312, was processed to investigate the authenticity of these reflections and their relationship to borehole geology. A dual scheme of the median filtering and F-K dip filtering was used. Tests with synthetic seismograms indicate the approach is effective at reasonable SNR levels. Downgoing energy is clearly identified but negligible upgoing energy is visible over random noise. These results indicate that lava flows and igneous
\end{abstract}


contacts in upper ocean crust have significant topography on lateral scales less than the Fresnel Zone $(\sim 300 \mathrm{~m})$ due to igneous and tectonic processes.

Keywords: East Pacific Rise, Vertical Seismic Profiling

\section{Introduction}

Though a large number of seismic experiments have been performed along and near the axis of the East Pacific Rise(EPR) (Detrick et. al., 1987, Harding et. al., 1993, Kent et. al., 1990 ), relatively few have investigated the structure of mature (>5 Ma) fast spreading crust in settings where crustal evolution can be studied with fewer geologic complexities. One exception is the study of Hallenborg et al. (2003), which presents results of a 15 Ma off-axis region in the Guatemala Basin, Eastern Pacific that was drilled at Site 1256 during ODP Leg 206 and IODP Expeditions 309 and 312. Multi-channel seismic (MCS) reflection and refraction data collected using the R/V Maurice Ewing in March-April 1999 were used to generate profiles along the flowlines and isochrons. Hallenborg et al.,2003 found a large number of bright reflectors, typically 1-5 km in lateral extent, something not seen near the axis of the EPR (Ranero et al, 1997). On the EPR, multichannel seismic profiles (Ranero et al, 1997) found sub-horizontal reflectors at $\sim 0.5-0.8 \mathrm{~s}$ within the basement, which is the expected depth of the seismic layer 2/3 transition, and $\sim 2 \mathrm{~km}$ long reflective segments deeper in the crust. The origin of the reflectors at Site 1256 is unclear, but Hallenborg et al. speculate that they maybe formed by off-axis faulting, off-axis magmatism (Benn et al, 1998) and fracture-induced hydrothermal alteration.

Figure 1 shows the final, processed reflection profile from the Hallenborg et al. survey that crossed Hole 1256D (Figure 3). The top-view of the area under study is shown in Figure 2. Site 1256 was chosen to penetrate thin crust formed at an ultrafast spreading rate because the depth to the top of the relict magma chamber would be minimized (Wilson et. al., 2003).

In the profile in Figure 1, several bright, laterally-coherent reflectors are visible at relatively shallow depths in the uppermost crust (5.2 to $5.6 \mathrm{sec}$ two-way travel time). We use a vertical seismic profile to investigate whether these features are real and, if so, to what geologic horizons they may correlate. This is the first experiment of its kind in terms of (1) depth of stratigraphic penetration through volcanic and dike layers into the gabbros and (2) presence of a nearly flat basement topography that eliminated defocusing and out-of-plane scattering events. 


\section{Geologic Setting}

The East Pacific Rise (EPR) segment being examined was formed early in the formation of the Cocos-Nazca spreading centre (CNS) by ultra-fast spreading ( 200mm/yr) along the Cocos-Pacific boundary during 11-18 Ma (Wilson, 1996). This spreading center originated by splitting the Farallon Plate at $\sim 23$ Ma (Barckhausen et al, 2001). The era of ultra-fast spreading ended at 10-11 Ma after the formation of the Panama Transform Fault over the CNS. Since then, the rate has slowed down to $140 \mathrm{~mm} / \mathrm{yr}$ (Wilcock, 1996). At the drill site, both water depth ( 3650m) and the depth to basement vary $<20 \mathrm{~m}$ over tens of kilometers (Leg 206, Prelimininary Report, Chapter 3). The sediment cover of about $275 \mathrm{~m}$ has two stratigraphic intervals, an upper silica-rich $\sim 70 \mathrm{~m}$ thick layer dating to $10 \mathrm{Ma}$ and a lower, older Miocene carbonate layer (Shipboard Scientific Party (2003b) Chapter 2). Refraction velocity increases from $4.8 \mathrm{~km} / \mathrm{s}$ at the basement surface to 6.5 $\mathrm{km} / \mathrm{s}$ to the bottom of the hole (Swift et al., 2008). The vertical velocity gradient decreases to $0.2 \mathrm{~km} / \mathrm{s}$ per $\mathrm{km}$ at about 1500 mbsf, marking the seismic layer $2 / 3$ boundary. The crustal thickness is about $5.4 \mathrm{~km}$. First arrival travel times from a vertical seismic profile (VSP) in the Hole 1256D indicate (1) $4.6 \mathrm{~km} / \mathrm{s}$ in a thin, ponded lava flow unit at the basement surface, (2) $4.1 \mathrm{~km} / \mathrm{s}$ in the underlying sheet flows and (3) an increase in velocity to $6.2 \mathrm{~km} / \mathrm{s}$ in sheeted dikes near the base of the hole (Swift et al, 2008).

\section{Synthetic Seismograms}

Using shipboard physical properties measurements in the sedimentary section above basement and the density and compressional velocity logs within basement from Expeditions 309 and 312, we computed 1- dimensional synthetic seismograms for a stack of horizontally uniform layers. A seismic response from Kennett \& Kerry, 1979 and Mallick \& Frazer, 1987 was implemented for a sample interval of $1 \mathrm{~ms}$ and a maximum modeled time of $8 \mathrm{~s}$. No attenuation was included (quality factor set to 9999). The Green's function is calculated assuming a diagonal moment tensor and is convolved with the source time function. The source signature used is a Ricker wavelet as shown in Figure 4 (Stephen et al, 1985). The time sample length of the source is $0.003 \mathrm{~s}$, total length is $8 \mathrm{~s}$ and delay assumed is $4.5 \mathrm{~s}$. This source function was chosen to match the shape of the seafloor reflection in the MCS profiles.

Figure 5 shows both synthetic and observed seismograms. This comparison shows that the sea-floor reflection in the MCS traces has the same signature and the same polarity as the synthetic source due to positive change in the impedance level at the seafloor. The waveforms of the MCS traces within the sediment section have higher amplitudes and shorter wavelengths 
than the waveforms within the basement. The synthetic seismograms show a significant peak at 4.9s and 5.2s, due to the seafloor and basement reflections respectively. These peaks correlate with features at similar times in the MCS traces. The red synthetic traces show sub-basement peaks in amplitude at 5.3s and 5.45s, visible above the noise and multiple levels because their amplitudes are comparable to the sea-floor reflection at 4.9s. These peaks in synthetic traces occur at about the same time as the smooth ripples of the MCS.

The MCS seismograms are a manifestation of the acoustic impedance and reflectivity changes of rocks near the hole. Hence, if significant reflectors do exist, the impedance log should indicate so. The impedance profile shows a slight step up at the seafloor and a considerable increase at the basement (Figure 5). The impedance changes below the basement are small, yet if the magnitude of the seafloor changes were to be considered in comparison, they cannot be ignored either.

\section{Vertical Seismic Profile}

To investigate the relationship between impedance changes within basement as well as the sub-basement peaks in the MCS seismograms, we processed the zero-offset vertical seismic profile obtained during IODP Expedition 312 to isolate the upgoing wavefield. The VSP collected on Expedition 312 was shot with a generator-injection airgun configured in harmonic mode with a 150 cc generator chamber and a 105 cc injector chamber. The airgun was suspended from a float at $7 \mathrm{~m}$ below the sea surface. The borehole receiver was a Schlumberger Versatile Seismic Imager (VSI) tool (Expedition 309/312 Scientists (2006)).

On Expedition 312, the VSP clamping depths were spaced 23 m, from $339 \mathrm{~m}$ to $1434 \mathrm{~m}$ below the sea floor, but borehole washouts forced spacing to deviate to up to $50 \%$. The VSP seismograms at 48 geophone stations had good signal to noise characteristics. The geophone stations were vertically arranged within the casing, down to the very bottom. The frequency bandwidth of the recorded VSP traces is $0-150 \mathrm{~Hz}$ and has a dominant frequency of $<75 \mathrm{~Hz}$. The bandwidth of the synthetics, via the time sample interval, was chosen to match the data. Figure 6 shows the amplitude spectrum of seismograms at one receiver depth.

The initial VSP record section is shown in Figure 10a - the entire section up to $4 \mathrm{~s}$ has been shown rather than a zoomed in section, which is more appropriate to discuss the processing. The first arrival of the down-going energy is evident from 2.6s to 2.9s. Any up-going energy that may be present after this arrival is not easily seen above incoherent noise. Traces with the best signal-to-noise ratio at each of the receiver stations were selected and stacked [Swift et. al. 2008]. Poor quality data was 
eliminated. The down-going energy is significantly attenuated due to geometric spherical spreading, intrinsic scattering and absorption. First arrival times were picked from the seismogram and were used to calculate interval velocity by Swift et. al. [2008].

Our processing included :

1. The data was demeaned.

2. Application of statics correction to align all the traces after incorporating their respective delay times. This helps to visualize the depth-time profiles better.

3. Spherical divergence correction of amplitudes by fitting an exponential curve of the form -

$$
a(r)=\frac{\exp (-\alpha r)}{r} \text { to }
$$
the data, by finding the best-fit where $r$ is the source-geophone offset. The difference of the observed amplitudes and theoretical curve values at each offset served as amplitude corrections (linear ramp gain compensation).

4. Low pass filtered to $87 \mathrm{~Hz}$ using a 3-pole, minimum phase Butterworth filter.

5. Considering an average velocity of $5 \mathrm{~km} / \mathrm{s}$ in the borehole region, the reflections from horizons at the bottom of the hole would reach the shallowest geophone at about 3.2s. For initial processing stages, data at times $<3.2 \mathrm{~s}$ were considered and the data beyond was muted and replaced by zeros.

6. Tapered and zero padded to double the length of the seismogram. Frequency-wave number (F-K) filtering to remove noise in the positive F-K quadrants and in the down-going wave. Dummy seismograms were padded above and below the VSP seismograms. Details are described in the following paragraph.

7. Median filtering to remove noisy spikes, bubble pulse due to the air gun, and remnants of the down-going wave.

8. Median filtering of the resultant seismogram to output any up-going components, if present.

The simplest way to prevent spatial aliasing is acquire data at a depth interval equal to half the shortest wavelength of interest. However with a mean seismometer clamping interval of $23 \mathrm{~m}$ and a minimum velocity of $4 \mathrm{~km} / \mathrm{s}$, the minimum unaliased wavelength of $46 \mathrm{~m}$ corresponds to a maximum frequency of $87 \mathrm{~Hz}$ (Yilmaz, 1985 and Hardage, 2000). The sampling interval is $1 \mathrm{~ms}$ hence the Nyquist frequency is $500 \mathrm{~Hz}$. However, a maximum resolvable frequency of $87 \mathrm{~Hz}$ was calculated to prevent spatial aliasing using a mean seismometer clamping interval of $23 \mathrm{~m}$ and a minimum velocity of $4 \mathrm{~km} / \mathrm{s}$. 
So a low-pass filter with a roll-off at $87 \mathrm{~Hz}$ was applied. This is in keeping with the amplitude spectrum shown which indicates most of the signal content to be present at frequencies $<100 \mathrm{~Hz}$ and also with the source signature which has a dominant frequency of $75 \mathrm{~Hz}$.

Theoretically, the amplitudes of seismic traces should decrease with propagation distance (in this case, depth) and time. To numerically implement this, the VSP seismograms are padded to double each dimension. The mean value of each seismic trace is used to pad the start and end of the time axis. Similarly, the last 4 traces are damped using successive taper functions and used to pad the space axis. This also helps to mitigate wraparound when the Fast Fourier Transform is applied to the seismogram. The original 48 traces are padded to 96, of which 10 are damped versions and the others represent the mean trend. Similarly, time samples are increased from 7500 (inclusive of source-delay) to 15000. This also helps to reduce noise generated by transformations of abrupt edges.

\subsection{Median Filtering}

Our approach begins by aligning the down-going wave (DGW) so that the arrival time of the direct wave is the same for each trace [Hardage, 2000]. Median filtering is used to remove glitches in data as well as enhance discontinuities that are vertically coherent along the direction of filtering. Akin to minimizing the L1 norm, median filtering rejects random noise and preserves periodic patterns. Thus, any event can be aligned and enhanced. Longer length filters reject dipping event multiples.

Because application of the median filter will enhance the DGW, we removed the DGW from the aligned seismograms by subtraction. On re-aligning back to original direct-wave arrival time, the traces should contain only the up-going wave, if any, and noise (Hardage, 2000). Based on results obtained using median filters with lengths of 5, 10, 20 (samples in Figure 7), a 5-point filter produces somewhat better signal to noise ratios. The results as seen in Figure 7 indicate that the median filter could not remove the downgoing wave completely by subtraction due to its varying signal amplitudes. To tackle this problem, we implemented an F-K filtering process to identify and eliminate the DGW in the seismograms after which the same median filtering technique was applied. Again, the comparison of the median filter lengths of 5, 10 and 20 is shown in Figure 8. Clearly, now the downgoing wave is completely removed. However, the application of the median filter increases the vertically coherent artifacts around $3.1 \mathrm{~s}$ (caused by the f-k filtering). These smeared artifacts are absent in Figure 7. It must also be noted that the noise in Figure 7 is small in amplitude compared to the leftover DGW, hence the visual scales of 
noise in Figure 7 and Figure 8 are different. This is because the traces at a depth of 600 mbsf and around 800 mbsf (as seen in the original seismogram of Figure 10a) have very large and noisy amplitude that get smeared over more depths after the application of the median filter. This effect increases with the length of the filter which is why a median filter of length 20 yields the noisiest seismogram. Henceforth, a length of 5 is used to minimize these artifacts. The second median filter is applied, as indicated in Step 8 of the processing outline, in order to extract the upgoing wave that may not be obvious within the noisy artifacts.

\section{2. $\quad$ F-K Filtering}

Frequency-Wavenumber filtering is a method for the separation of the UGW and DGW based on the direction of propagation in space and hence the difference in sign of the apparent velocity or $\mathrm{f} / \mathrm{k}=\mathrm{z} / \mathrm{t}$ (Hardage, 2000). In the F-K domain, the UGW maps to the negative $\mathrm{f} / \mathrm{k}$ i.e. the second and fourth quadrant and the DGW maps to the positive $\mathrm{f} / \mathrm{k}$ i.e. the first and third quadrant. Thus, by suppressing the appropriate quadrant either by a zero-valued filter or a horizontal contour-dependent slice filter (Suprajitno and Greenhaigh, 1985), the wave in question can be eliminated. Care was taken to taper sudden change around the axes to prevent Gibbs phenomenon due to a step function cutoff.

Figure 9a shows the F-K spectra obtained by zeroing traces except for a $0.3 \mathrm{~s}$ ( $2.6 \mathrm{~s}$ through $2.9 \mathrm{~s}$ ) window around the DGW section of the transformed seismograms. Only the first and second quadrant of the F-K spectra has been shown, thus frequencies are negative. A clear lineation is seen, indicating that the transform accurately maps the direct wave. There is no reflected energy in the negative quadrant because we passed only the direct wave in the window. Figure 9b shows the f-k spectra of the seismograms that were time-windowed from the end of the 0.3s DGW (i.e. at 2.9s) up to 3.2s, which is the time at which a reflection off horizontal strata below the bottom of the Hole 1256D should arrive at the uppermost geophones. The f-k spectra for a time window from 3.2s to 3.6s was also plotted. Any UGW energy in this window, if at all present, would have been weaker than that observed in Figure 9b. Coherent arrivals beyond 3.2s correspond to reflections below the bottom of the hole and to multiples. Figure 7b contains no identifiable lineation over random noise levels. The down-going lineation is not visible in these figures because the time window used does not encompass it.

The final seismogram record sections is shown in Figure 10b alongside the unprocessed, unfiltered VSP seismograms in Figure 10b. Clearly, the DGW has been suppressed however even in its absence, coherent signals cannot be identified. 


\subsection{Test Results on Synthetic Seismograms}

To check whether our filtering technique works to image upgoing waves, we applied the technique to VSP seismograms to which synthetic reflections had been added.. An impulse response at the right time and amplitude to simulate an up-going wave reflected from a horizontal surface with a reflectivity coefficient of one was generated. The code was run for reflecting surfaces at three borehole depths: 450 mbsf, 1060 mbsf and 1270 mbsf. Reflectivity coefficients have negative sign to flip the polarity of the down-going pulse. Move-out of reflections is governed by the move-out of the P-arrival times. Up-borehole decay of amplitude of reflection coefficients is governed by the downward decay of the direct-wave amplitude. All the reflections were summed. A short segment of the down-going P arrival from the first receiver trace was cut and convolved with the array of impulse responses to simulate reflected waveforms. The resulting seismograms are shown in Figure 11a. The seismograms have been zoomed in to the time panes which are being discussed. When the filtering algorithm described in the previous sections was applied to this synthetic, the upgoing waves were distinctly isolated as shown in Figure 11b. From the first figure, the third upgoing wave visually obvious over the noise levels however this wave is clearly isolate after the filtering algorithm has been performed. The algorithm also clearly brings out the first two upgoing waves which in the first figure are immersed amidst noise. Both the figures have been generated for a reflection coefficient of 0.25. From our impedance log, we compute reflection coefficients of 0.35 at a depth of 250 mbsf and a coefficient of 0.3 at a depth of 650 mbsf. The synthetic seismograms suggest that the basement coefficient is not more than $0.45-0.5$, and the above subbasement coefficient estimates are clearly lower. Thus it is reasonable to expect coherent vertically reflected energy to be recorded by the borehole seismometers and processed by the given, had upgoing energy actually been present.

The reflected part of the synthetic traces were then multiplied by 1 to 0.1 sequentially in steps of 0.1 , convolved with the pulse, added to the original VSP traces and the filtering code was re-run. This will have the effect of simulating smaller more realistic - reflection coefficients. The results indicate that our filtering approach detects reflections with amplitudes down until $20 \%$ of the direct wave with realistic noise conditions. The filtering also removes the bubble pulse from the original data. Although the two figures look very similar in terms of enhancing the upgoing wave in its absolute value, the filtering step is essentially especially in the case more downgoing waves and ghost reflections were to be present - in which case, the upgoing wave is not very easy to identify with the naked eye. Since our filtering algorithm works well for synthetic models of upgoing waves over a range of reflection coefficients, it is expected to work for the Hole 1256D VSP traces as well, if there is any upgoing energy. The DGW spectra of the synthetic model is shown in Figure 9a, which remains the same 
as before. The UGW that is synthesized is shown in Figure 11. As the reflection coefficient decreases from 0.8 to 0.5 to 0.2 (Figure 12a, 12b, 12c respectively), the trace of the UGW in the spectra becomes increasingly difficult to identify over the noise levels recorded as shown in the FK spectra of the UGW section. Note that values of the noise levels of the original seismogram spectra as seen in Figure 9 remain the same, but in spite of these noise levels even with a reflection coefficient as low as 0.2 , Figure 12c shows that the synthetic upgoing wave can be identified. This demonstrates that if upgoing energy greater than the $20 \%$ of the downgoing wave energy had been present in the VSP data, the F-K spectra would have been able to identify it.

\section{Conclusions}

The objective of this analysis was to determine if the laterally coherent events observed in the MCS profile are real, and if so, to determine what geologic features are responsible. Synthetic seismograms, based on the borehole logs in the basement, indicate that there are impedance contrasts that could generate reflections. However, the timing of the synthetic reflected arrivals does not agree with the timing of the MCS basement reflections. The MCS traces, although they show some evidence of reflections, may not be dependable because the processing was not focused primarily on imaging reflections at shallow, sub-basement depths. Both the median filtering and the f-k transforms of the VSP traces did not reveal coherent reflected energy and this result conflicts with the synthetic seismogram result. Attenuation cannot explain the absence of reflections because the changes in amplitude with depth in the direct wave are insufficient to dampen the amplitude of reflected energy over the $\sim 100 \mathrm{~m}$ that would be required to image a coherent up-going reflection. It is likely, then, that the impedance contrasts derived from the borehole logs are not flat, planar surfaces, an assumption inherent in the computation of the 1-D synthetic seismograms. Energy is probably scattered rather than reflected in coherent up-ward traveling waves.

The agreement between the sonic log velocity and the VSP velocities obtained from the direct wave arrival times indicates that these logs are good representations of the vertical change in physical properties. The lack of reflected energy in the VSP traces, however, indicates that there must be topography on horizontal scales less than the Fresnel Zone. Swift et al 2008) computed a diameter of 160-200 $\mathrm{m}$ for the seafloor Fresnel Zone. The absence of reflected energy in the filtered seismograms indicates that sub-basement structures have relief of at least $25 \mathrm{~m}$ (one quarter wavelength at $5 \mathrm{~km} / \mathrm{s}$ and $50 \mathrm{~Hz}$ ) over lateral distances of a few hundred meters. The lack of reflected energy in the VSP seismograms also indicates that the laterally coherent reflections in the MCS profiles are likely artifacts of processing. 
The E312 VSP data, thus, reveals no sub-basement reflections over and above the random noise of the data. The acoustic impedance profile shows significant variability below basement, comparable to change at the sea-floor. Similarly, the synthetic seismograms show a similar sub-basement spike (in phase) as the source signature and sea-floor reflection. The latter two serve dependable pillars of comparison. These results indicate that sufficient impedance contrasts occurs in the borehole rocks to produce reflections; their absence means their lateral extent is small compared to the Fresnel zone.

Unfortunately, the geophones of the VSP survey are all placed below the basement and hence, cannot record any of the dependable reflections above it, which could serve as yardsticks to analyze the approximate amplitude of reflected energy at the survey area. If this information were available, an appropriate contour level could be defined below which noise level could be eliminated. In the absence of such, no reflective energy can be identified over the apparent noise level of the f-k spectra.

As a suggestion for a future program, a VSP drill-hole that penetrates beneath the basement could potentially be a very powerful tool to identify sub-basement reflections provided good data quality is available for receiver locations both above and below the basement surface.

\section{Discussion}

It is possible that wide-angled reflections may occur even in the case where there is no vertical reflection, thus the VSP processing presented in this paper may not be sufficient condition in eliminating their absence in the geographical area studied. There could be two ways in which this is possible: (a) Diving ways produced by laterally coherent vertical velocity gradients that could be processed and interpreted as reflections during MCS processing and (b) steep vertical velocity gradients that would appear as just steep vertical velocity gradients in vertical incidence at 40-50 Hz and not produce reflections. However, they might appear as a sharp interface to a $10 \mathrm{~Hz}$ wave. The authors also acknowledge that synthetic data results are a necessary but not sufficient condition for exactly same results on real data. The conclusion of the paper has been drawn putting together results of various angles of analysis, all of which indicate negative results. In themselves, none may be standalone proof, but together, they strongly support the authors' conclusions. 


\section{Acknowledgements}

We are extremely grateful to Dr. Ralph A. Stephen for spending hours of time discussing the various theories and research advancements in fields of my interest, eventually helping me choose this topic, Dr. J.A. Collins, Department of Geology and Geophysics, Woods Hole Oceanographic Institution for allowing us to use his synthetic seismogram reflectivity code and to the unknown reviewers who helped us significantly improve the quality of this manuscript.

\section{References}

Barckhausen, U., C. R. Ranero, R. von Huene, S. C. Cande, and H. A. Roeser (2001), Revised tectonic boundaries in the Cocos Plate off Costa Rica:Implications for the segmentation of the convergent margin and for plate tectonic models, J. Geophys. Res., 106, 19,207-19,220.

Benn, K., A. Nicolas, and I. Reuber (1988), Mantle-crust transition zone and the origin of wehrlitic magmas: Evidence from the Oman ophiolite, Tectonophysics, 151, 75-85.

Bolmer, S.T., et. al. (1992), Vertical Seismic Profile at Site 765 and Seismic Reflectors in the Argo Abyssal Plain, Proceedings of the Ocean Drilling Program, Scientific Results, Vol 123 - edited by F.M. Gradstein, J.N. Ludden, et. al.

Detrick, R. S., P. Buhl, E. Vera, J. Mutter, J. A. Orcutt, J. J. Madsen, and T. Brocher (1987), Multi-channel seismic imaging of a crustal magma chamber along the East Pacific Rise, Nature, 326, 35- 41.

Hardage, BA (2000), Vertical seismic profiling: Principles, Pergamon Print, $3^{\text {rd }}$ Edition.

Harding, A. J., G. M. Kent, and J. A. Orcutt (1993), A multichannel seismic investigation of upper crustal structure at 9N on the East Pacific Rise: Implications for crustal accretion, J. Geophys. Res., 98, 13,925- 13,944.

Hallenborg et. al. (2003), Seismic structure of 15 Ma oceanic crust formed at ultrafast spreading East Pacific Rise : Evidence for kilometer-scale fracturing from dipping reflectors, Journal of Geophysical Research, Vol 108, No. B11, 2532, doi : 10.1029/2003JB002400.

B.L.N. Kennett and N.J. Kerry (1979), Seismic Waves in a stratified half-space, Geophys. J.R. astr. Soc., 57, $557-583$.

Kent, G. M., A. J. Harding, and J. A. Orcutt (1990), Evidence for a smaller magma chamber beneath the East Pacific Rise at 9_300N, Nature, 344, 650-653.

Mallick, S. and L.N. Frazer (1987), Practical aspects of reflectivity modeling, Geophysics, Vol 52, No. 10, $1355-1364$. 
Suprajitno, M., and S.A. Greenhaigh (1985), Separation of upgoing and downgoing waves in vertical seismic profiling by contour-slice filtering, Geophysics, Vol. 50, N0.6, 950-962.

Stephen, R.A., et. al. (1985), Finite Difference synthetic acoustic logs, Geophysics, Vol 50, No. 10, 1588-1609.

Stewart, R.R. (1985), Median Filtering : review and a new F/K analogue design, Journal of the Canadian Society of Exploration Geophysicists, Vol. 21, No. 1, 54-63.

Swift S., M. Reichow, A. Tikku, M. Tominaga, L. Gilbert (2008), Velocity structure of upper ocean crust at Ocean Drilling Program Site 1256, Geochem. Geophys. Geosyst., 9, Q10O13, doi:10.1029/2008GC00218.

Teagle, D.A.H., Alt, J.C., Umino, S., Miyashita, S., Banerjee, N.R., Wilson, D.S., and the Expedition 309/312 Scientists (2006), Proc. IODP, 309/312: Washington, DC (Integrated Ocean Drilling Program Management International, Inc.). doi:10.2204/iodp.proc.309312.2006.

Wilcock, W. S. D., S. C. Solomon, and D. R. Toomey (1995), Seismic attenuation structure of the East Pacific Rise near 9300N, J. Geophys. Res., 100, 24,147- 24,165.

Wilson, D. S. (1996), Fastest known spreading on the Miocene Cocos-Pacific plate boundary, Geophys. Res. Lett., 23, 30033006.

Wilson, D.S., D.A.H. Teagle, G.D. Acton, er. Al. (2003), Shipboard Scientific Party (2003b), Site 1256, in Proc. ODP, Init. Repts., 206. Availiable from : Ocean Drlling Program, Texas A\&M University, College Station TX 77845-9547, USA.

Yilmaz, O. (2001), Seismic data Analysis - Processing, Inversion, and Interpretation of Seismic Data, Society of Exploration Geophysicists(Editor: S. Doherty).

Zimmerman, L.J., and S.T. Chen (1993), Comparison of Vertical Seismic Profiling techniques, Geophysics, Vol. 58, No. 1, 134-140.

\section{Figure Captions}

Figure 1: Travel-time (sec) MCS profile across Hole 1256D. Processing by Hallenborg et al. (2003) included stacking, poststack time migration, and depth-dependent amplitude scaling. No additional amplitude scaling was applied. Dashes mark VSP travel times to lithologic boundaries described in Wilson et al. (2006): (1) top of Inflated Flows, (2) top of Sheet and Massive Flows, (3) Transition Zone, and (4) top of Plutonic section. 
Figure 2: Map of the seafloor in the Eastern Pacific. Hole 1256D was drilled by the drilling legs L206, E309 and E312.

Figure 3: CDP navigation for Ewing 9903 shows location of Line 22 with respect to Hole 1256D

Figure 4: Source waveform used for computing the synthetic seismograms in Figure 4.

Figure 5: The red traces are synthetic seismograms generated using a Ricker Wavelet as a source and a horizontally uniform medium of 716 layers. The blue trace is the multichannel seismic profile at shot point 5300 of Figure1. The first red traces (left) are the synthetics generated without surface reflections or multiples and the second set of red traces (right) has no surface reflections but has multiples. The multiples are much larger in amplitude in the subbasement levels and thus in the visual scale of the figure, do not show much difference in times $<5$ s. The pink profile is the impedance log (product of the velocity and density) used as an input to the synthetic seismogram code.

Figure 6: VSP seismograms and spectra from 339 mbsf recorded during Leg 312 include a first arrival at $2.61 \mathrm{sec}$ and a bubble pulse arrival at $\sim 2.71$ sec. Negative pressure is up. Peak spectral power occurs at $<75 \mathrm{~Hz}$. Signal spectra are computed on $0.5 \mathrm{sec}$ segments that begin with the first arrival. The noise spectra are computed on the 0.5 sec segment that just precedes the first arrival. Red lines are spectra of traces 1-3; blue line is the spectra of the stacked seismogram.

Figure 7: Results of applying (from left to right) a 5, 10 and 20 point median filter on the spherical divergence corrected VSP seismograms. Clearly, applying only this method does not remove the down-going wave. Instead, large and noisy amplitudes in the original seismogram of Figure 10a get smeared over more depths after the application of the median filter. The aspect ratio for this figure is more than that in Figure 10 to highlight the effect of the filter. 
Figure 8: Results of applying (from left to right) 5, 10 and 20 point median filter to the spherical divergence corrected VSP seismograms on which an F-K filtering has been first performed to remove. the positive downgoing propagation wave. Used in this sequence, median filtering wipes out the remnants of the downgoing wave and removes solitary glitches instead of smearing the noise like in Figure 7a. The aspect ratio for this figure is more than that in Figure 10 to highlight the effect of the filter.

Figure 9a: F-K spectra of the down-going wave (time windowed from 2.6s to 2.9s).

Figure 9b: Spectra of the seismograms, time windowed from 2.9s to 3.3s (i.e. 0.3s) after the DGW do not reveal traces of an immediate UGW from the bottom of the hole. Absence of UGW at within this time window implies that either coherent reflectors do not exist or that the UGW is too weak to be identified over noise levels. Thus, any arrivals beyond 3.3s would be even weaker and indistinguishable.

Figure 10a: Initial, un-filtered VSP seismograms from E312.

Figure 10b: Final seismograms after F-K filtering and median filtering. The down-going wave has been removed, but no inclined up-going wave is seen. The vertically coherent energy is noise enhanced by filtering. The seismograms have been amplified by 5 times more gain than the other figures to illustrate the absence of the UGW.

Figure 11a: Synthetic seismogram test of our filtering approach to image up-going energy. (a) Impulse seismograms generated at depths 450 mbsf, 1060 mbsf, 1270 mbsf by synthetic reflectors are convolved with the downgoing pulse shape, scaled and added to the original VSPs to simulate upgoing wave energy.

Figure 11b: The results of applying our filtering algorithm to these synthetics show that the filters are sufficiently robust to image the upgoing energy.

Figure 12a: Enlarged section showing the upgoing energy quadrant of the FK spectra of the synthetic seismograms with a reflection coefficient of 0.8 assumed on all three horizons. 
Figure 12b: Enlarged section showing the upgoing energy quadrant of the FK spectra of the synthetic seismograms with a reflection coefficient of 0.5 assumed on all three horizons.

Figure 12c: Enlarged section showing the upgoing energy quadrant of the FK spectra of the synthetic seismograms with a reflection coefficient of 0.2 assumed on all three horizons. Upgoing energy can still be identified over the noise levels.

\section{FIGURES AND TABLES}

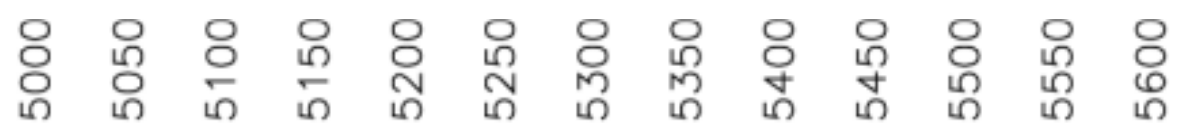

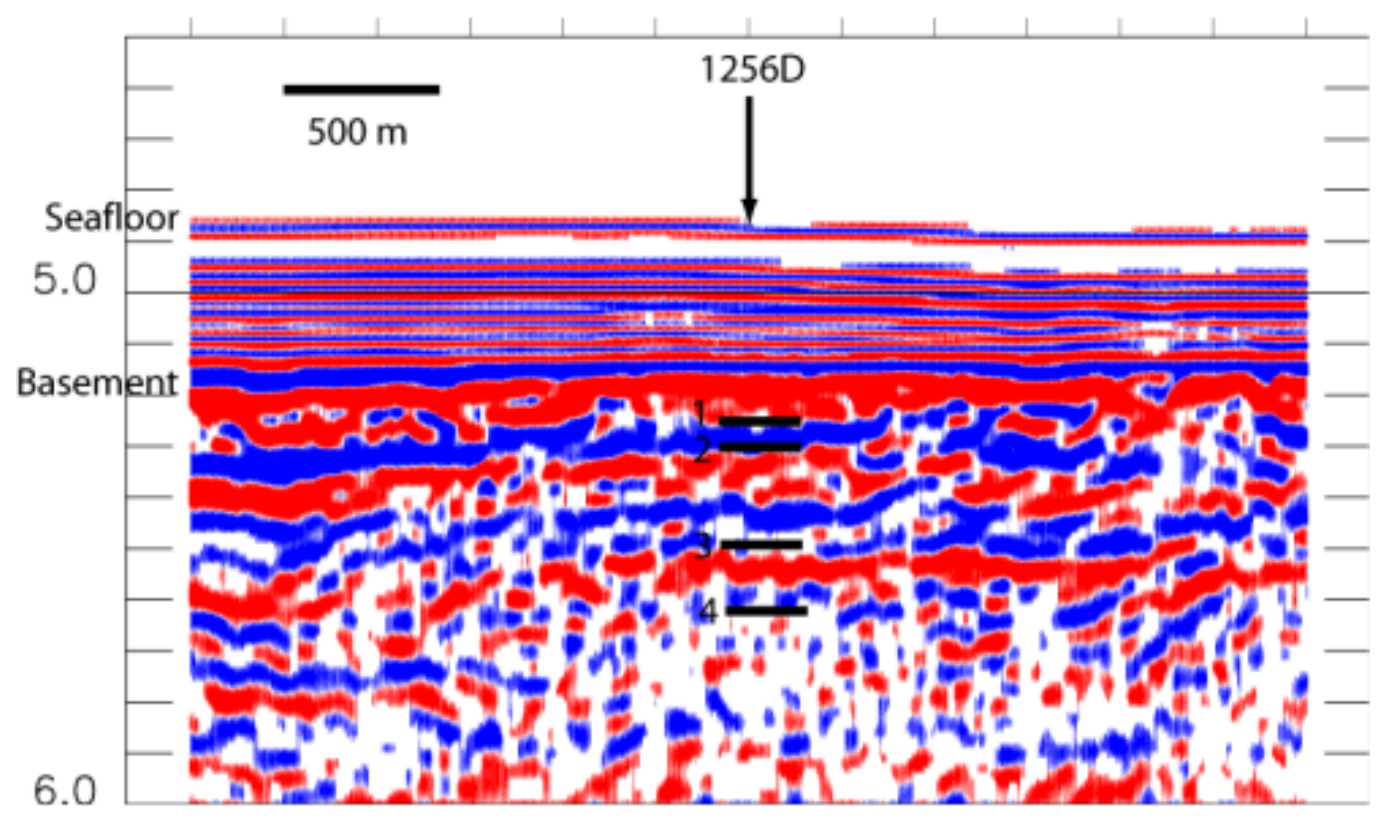

Figure 1 


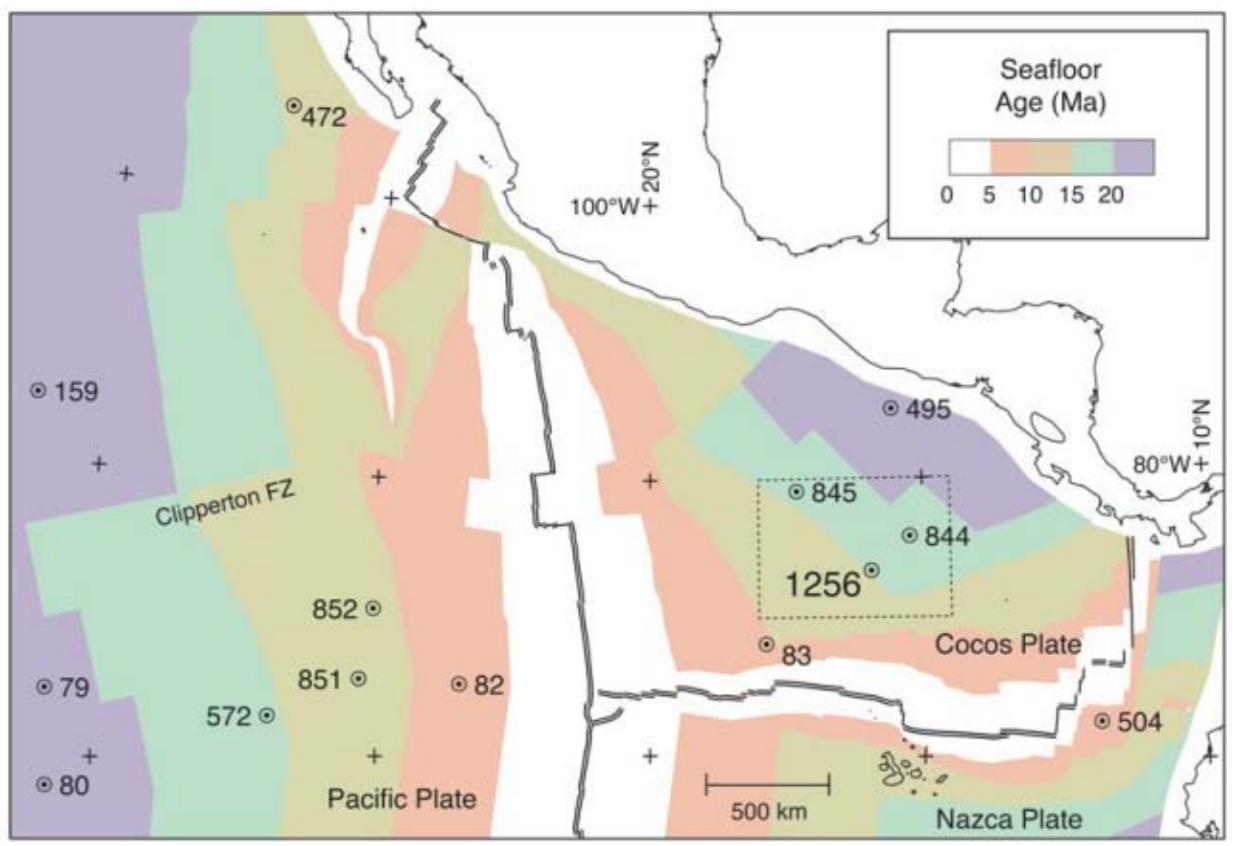

Figure 2

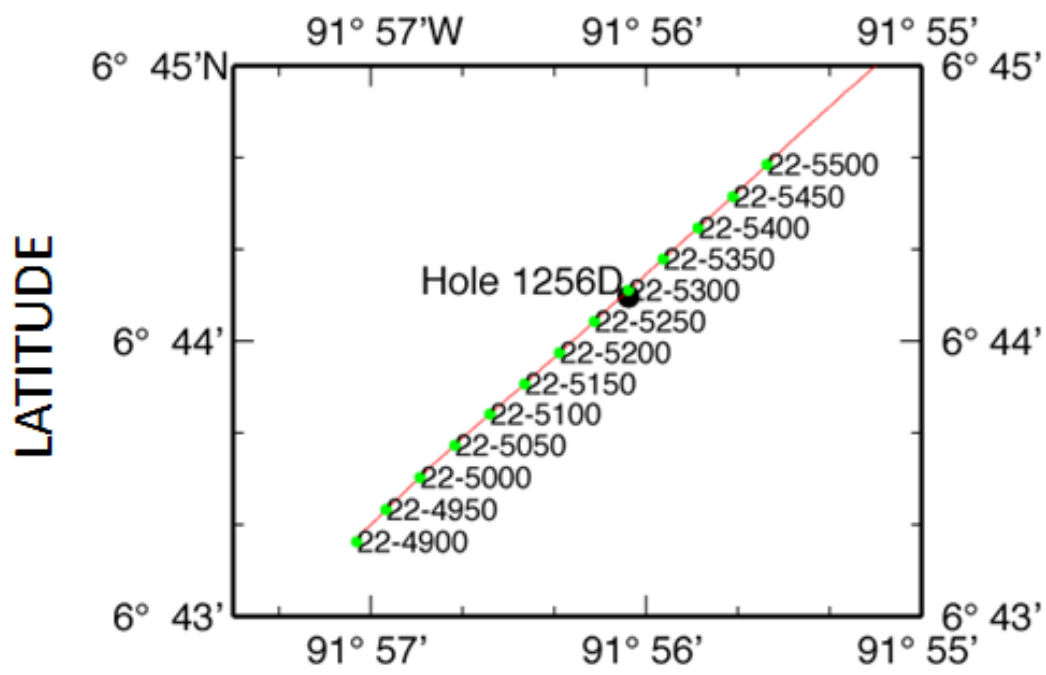

LONGITUDE

Figure 3 


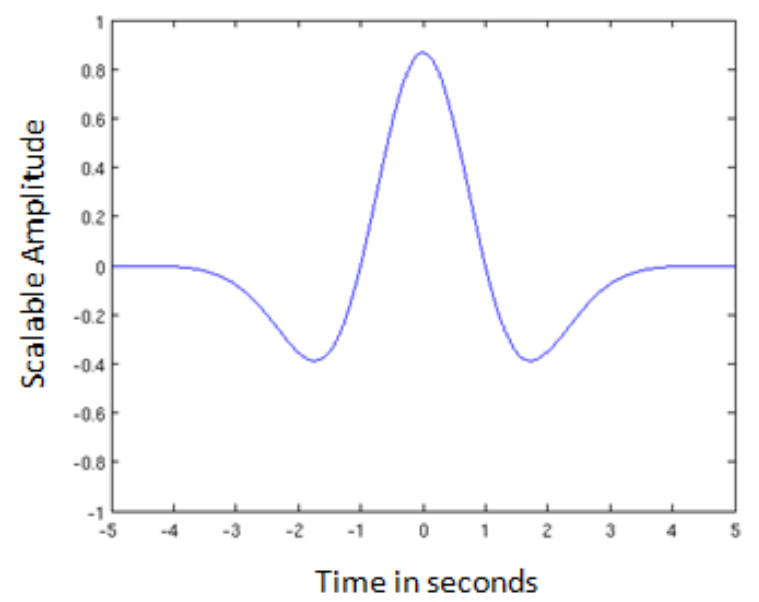

Figure 4

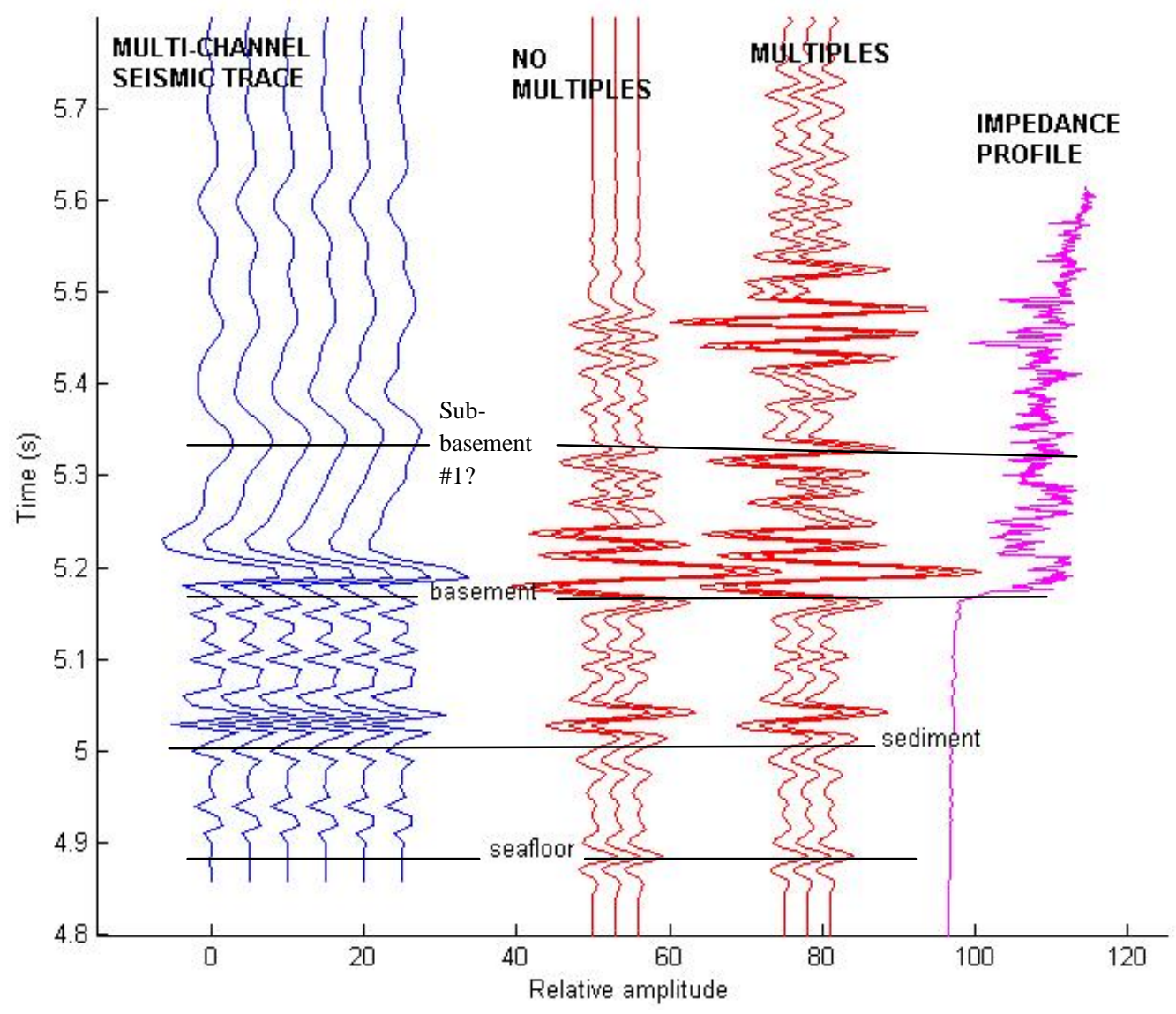

Figure 5 

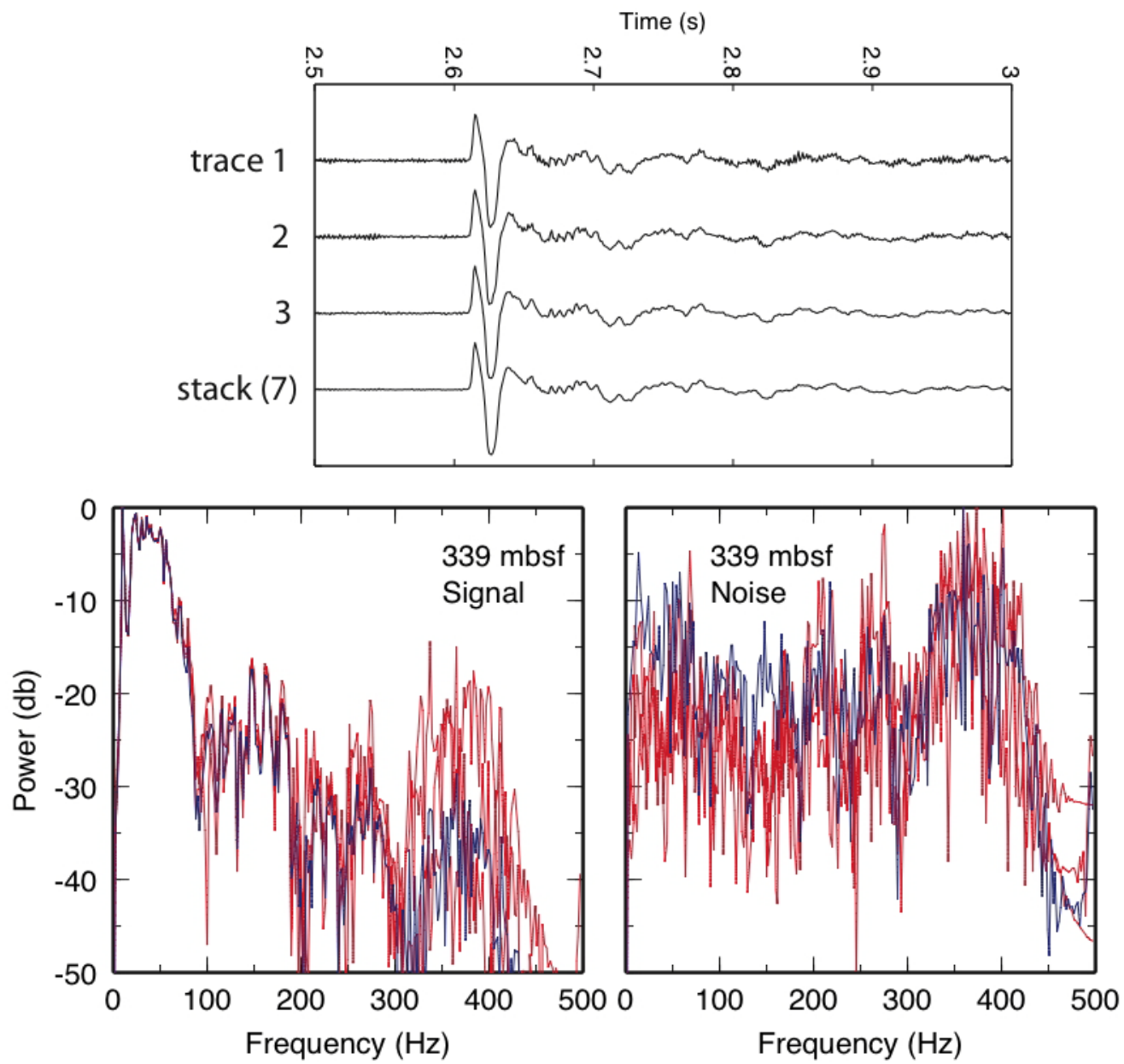

Figure 6 

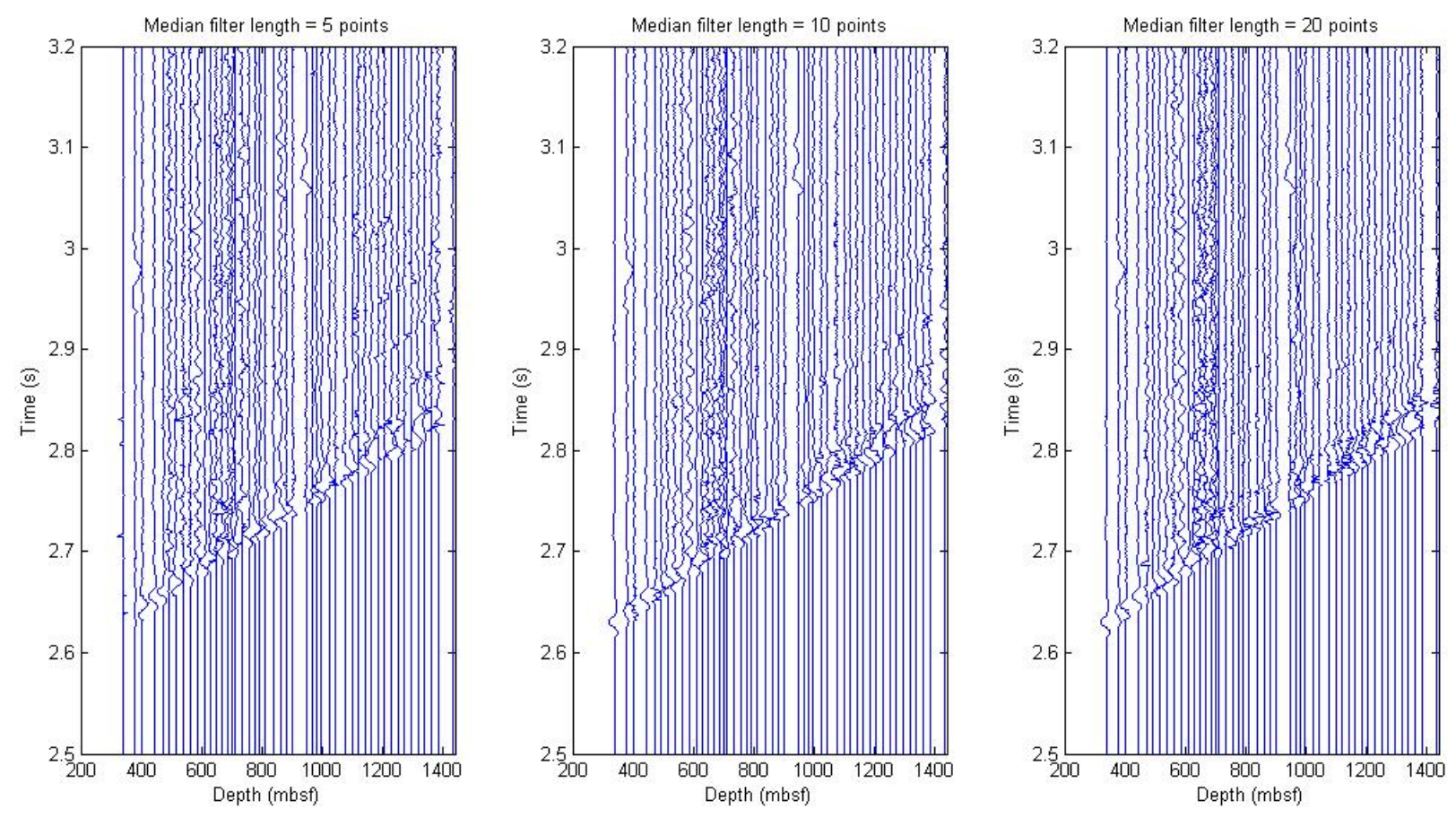

Figure 7: From left to right - a, b, c
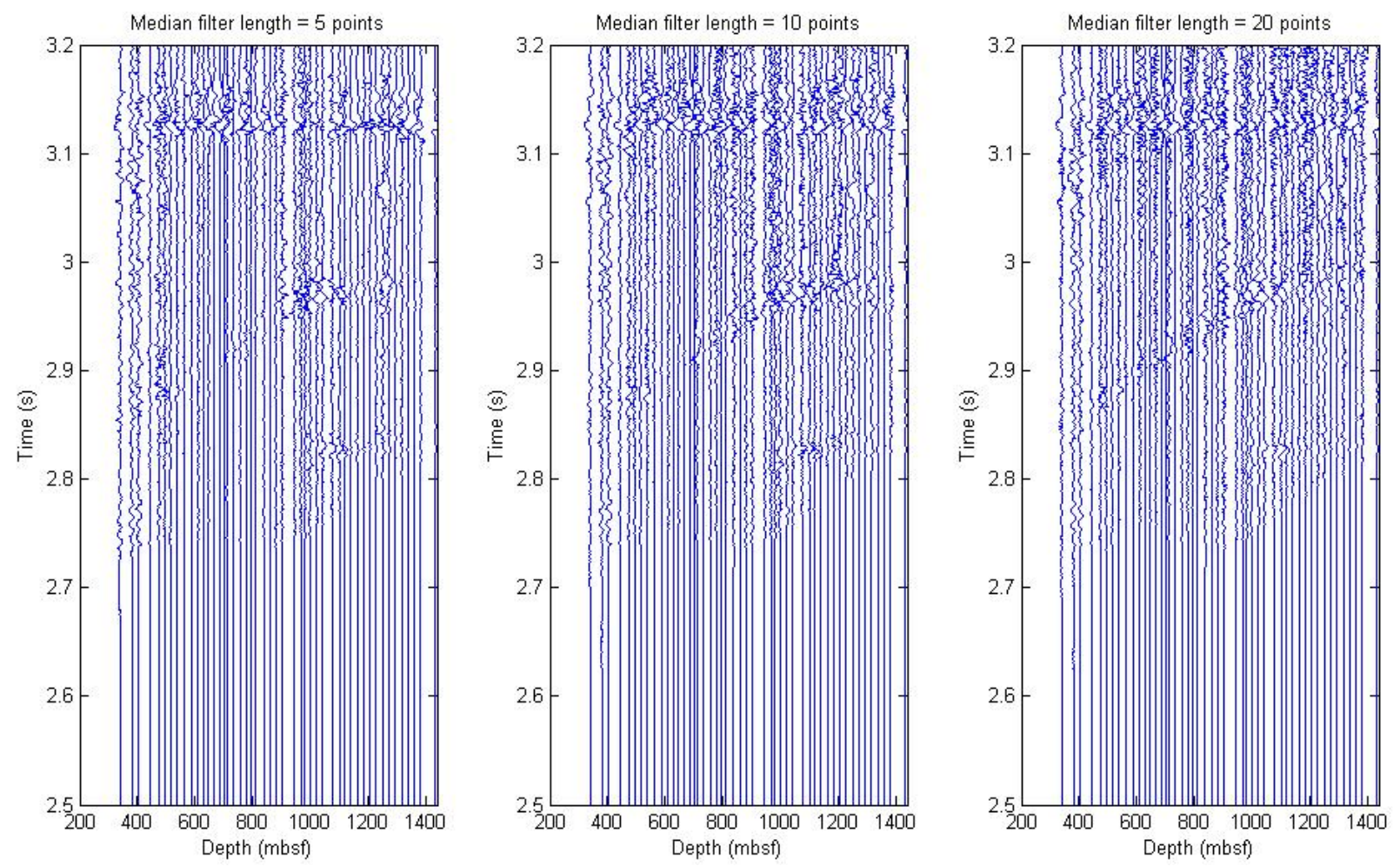

Figure 8: From left to right - a, b, c 

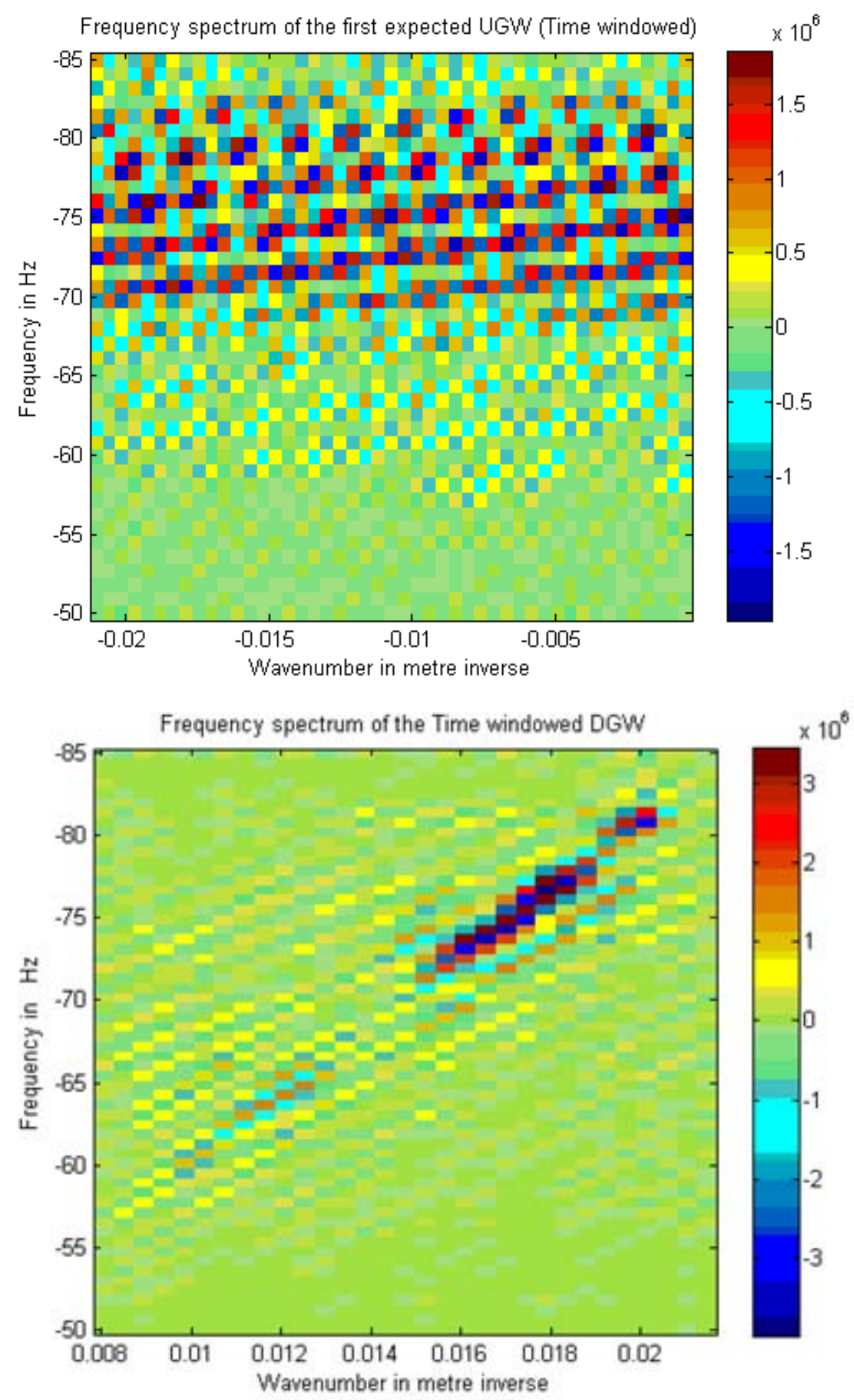

Figure 9: From top to bottom - a, b 

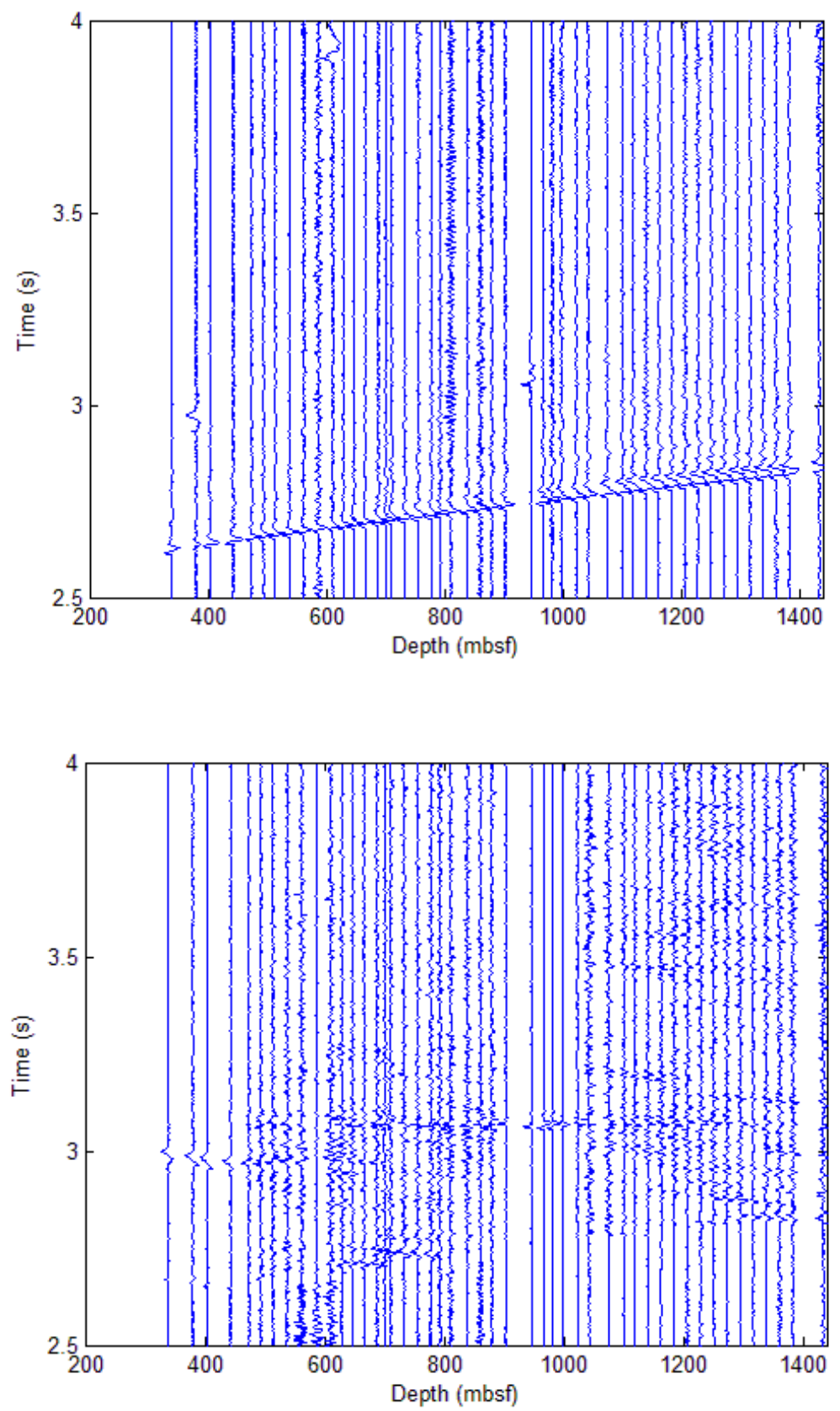

Figure 10: From top to bottom - a, b 

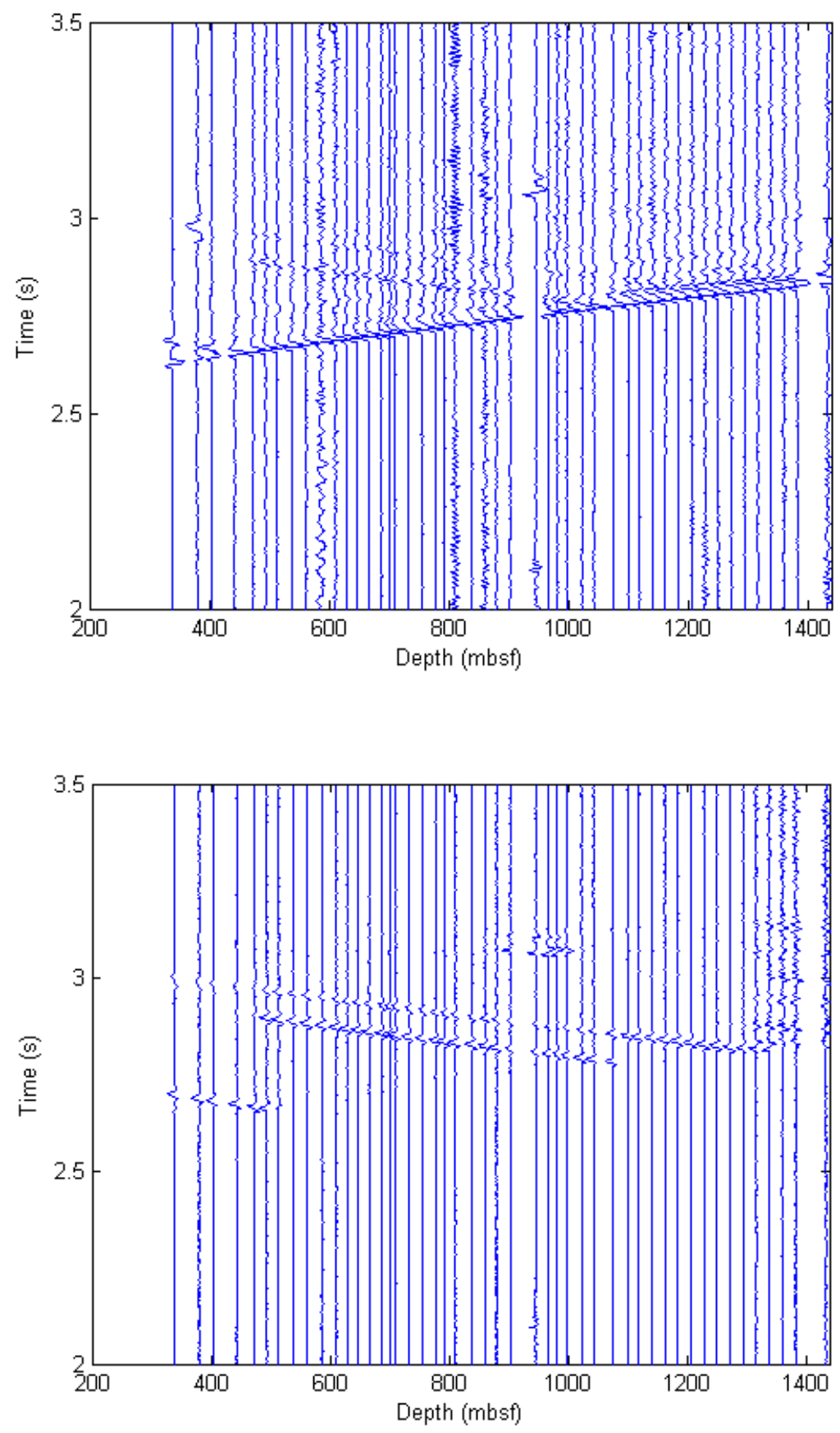

Figure 11: From top to bottom - a, b 

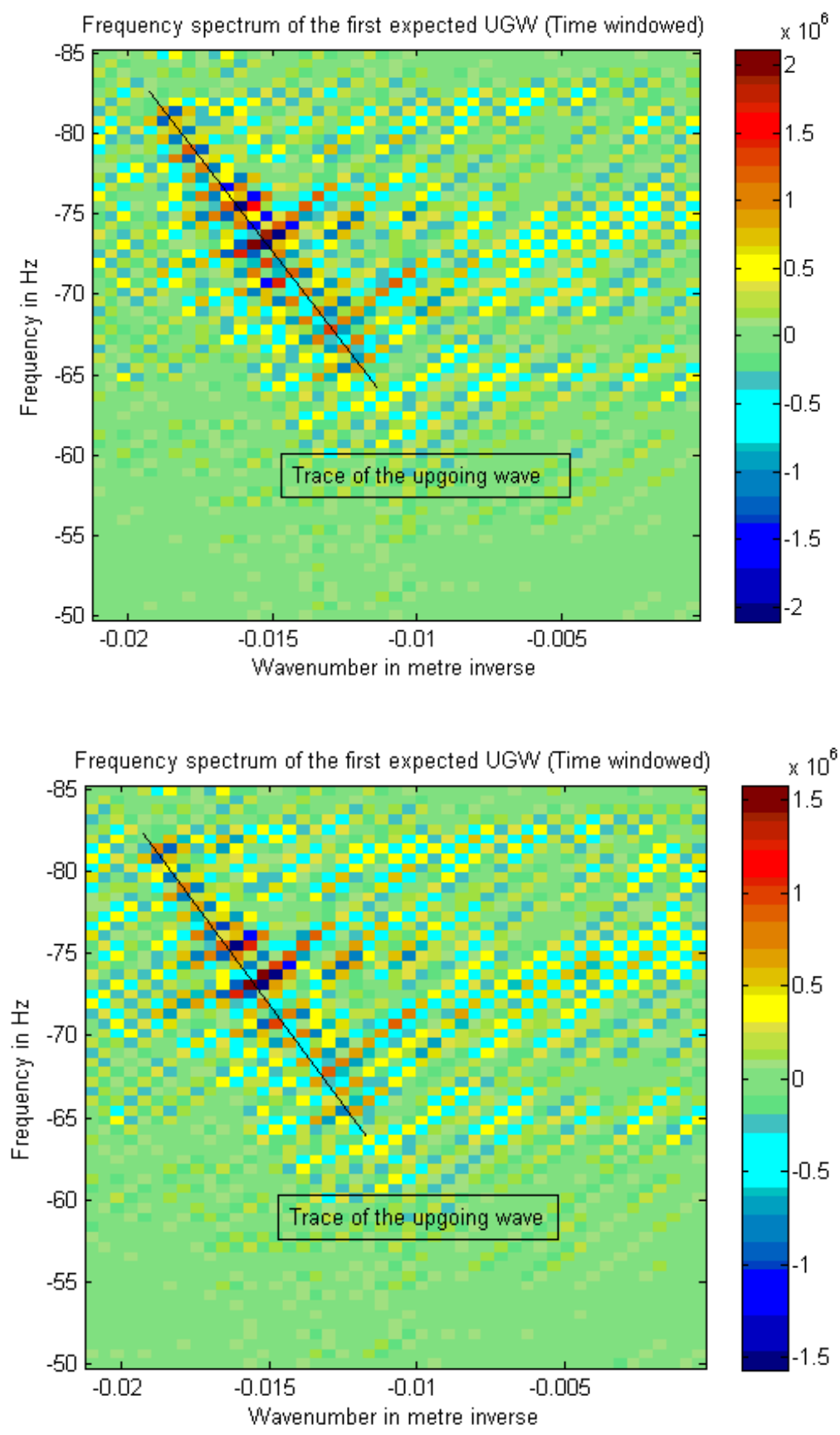

Page 23 of $\mathbf{2 4}$ 


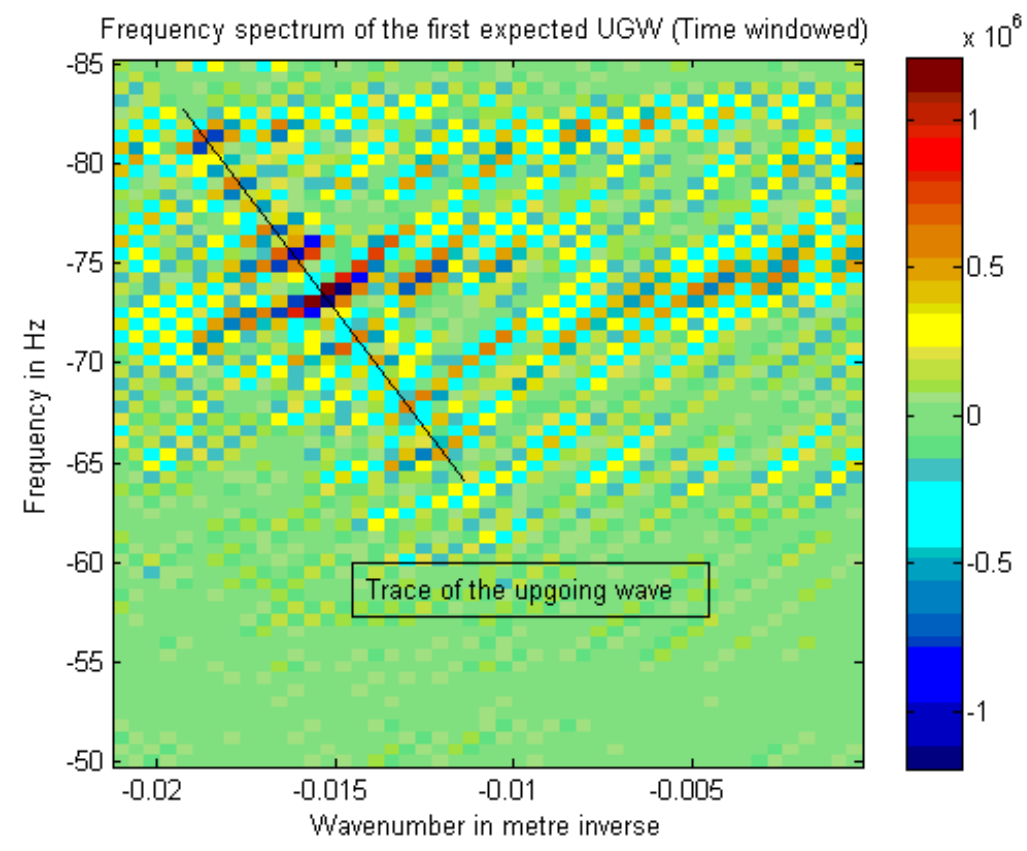

Figure 12: Top to Bottom - a, b, c 